\title{
A propósito de Diálogos españoles del Renacimiento: balance (parcial) y perspectivas de investigación
}

\author{
Donatella Gagliardi \\ Università della Calabria \\ donatella.gagliardi@unical.it
}

Recepción: 16/10/2015, Aceptación: 19/10/2015, Publicación: 22/12/2015

\section{Resumen}

Pasando revista a las más recientes contribuciones al estudio del género dialógico, se presta especial atención a tres de los autores incluidos en la antología Diálogos españoles del Renacimiento (2010). Se presentan nuevos datos acerca de su biografía y de la transmisión de sus obras, que permiten sugerir futuras líneas de investigación.

Palabras clave

género dialógico; Renacimiento; perspectivas de investigación

\begin{abstract}
About Diálogos espańoles del Renacimiento: (partial) appraisal and research prospects This review of the most recent contributions to dialogue genre studies gives special attention to three of the authors included in the anthology Diálogos españoles del Renacimiento (2010). New facts about their lives and the transmission of their works are presented, suggesting future areas of research.
\end{abstract}

Keywords

dialogue genre; Renaissance; research prospects 
A cinco años de la aparición del ponderoso volumen colectivo coordinado por Ana Vian, ${ }^{1}$ en el ámbito hispanista los estudios sobre el género dialógico, especialmente en la cultura aurisecular, gozan de una salud boyante. Excelentes síntomas de ello son algunos recientes congresos y publicaciones, ${ }^{2}$ fruto, en buena parte, de la efervescencia investigadora del equipo dirigido por la misma Ana Vian y por Consolación Baranda, ${ }^{3}$ que ha propiciado, entre otras iniciativas, la creación de Dialogyca BDDH. ${ }^{4}$

Ascienden a 227 los registros (de libre acceso) que se han elaborado desde el arranque del proyecto «Biblioteca Digital de Diálogo Hispánico» hasta la fecha. ${ }^{5}$ Algunos de ellos están dedicados a obras que en su momento se seleccionaron para la antología de la Biblioteca de Literatura Universal, como es el caso de los diálogos de Francisco López de Villalobos, editados en 2010 por Consolación Baranda, quien es autora también de las correspondientes fichas en Dialogyca.

En las páginas que siguen me voy a detener precisamente en estos escritos del médico y humanista zamorano, juntos con el anónimo Diálogo entre Caronte y el ánima de Pedro Luis Farnesio, y los Diálogos de apacible entretenimiento de Gaspar Lucas de Hidalgo, por ser los tres textos (o conjuntos de textos) que recibieron entonces, en palabras de Ana Vian, «su primera edición con fundamento crítico». ${ }^{6}$

La brillante y versátil personalidad del doctor Villalobos nunca ha dejado de fascinar a los historiadores tanto de la medicina como de la literatura. Dos facetas de su trayectoria biográfico-profesional han despertado más que otras el interés de estos últimos: la maestría en el arte de motejar, y la singular condición de converso reconocido, empeñado en no ocultar, cuando no en ostentar con humor descarado, su linaje judío. Sin embargo, a su obra literaria no se le ha prestado toda la atención filológica que merecería, y buena prueba de ello es el hecho de que sigue leyéndose, en su casi totalidad, en ediciones del XIX (in

1. Ana Vian coord. (2010). Reúne un florilegio de los siguientes autores: Francisco López de Villalobos, Alfonso de Valdés, Cristóbal de Villalón, Juan de Jarava, Fernán Pérez de Oliva, Francisco de Sosa, Pedro de Mercado, Pedro de Navarra, Gaspar Lucas Hidalgo, además de los anónimos Diálogo entre Caronte y el ánima de Pedro Luis Farnesio, y Diálogo de Scipión Africano y Sócrates. La antología va precedida por una extensa y exhaustiva introducción, una muy útil cronología (ambas al cuidado de Ana Vian), y la bibliografía de las obras citadas.

2. Véanse, por ejemplo, el coloquio «Dinámicas de negociación. Nuevas tendencias de investigación sobre el diálogo iberorrománico renacentista y su contexto discursivo» celebrado en diciembre de 2013 en la Ruhr-Universität Bochum, y el congreso internacional «Diálogo y censura en el siglo XVI», que tuvo lugar en junio de 2014 en la Universidad Complutense de Madrid, y cuyas actas están ahora en prensa. Entre las monografías recién salidas cabe destacar la de Jesús Gómez (2015), y la de Santiago del Rey Quesada (2015), que se basa en su tesis doctoral (2012), dirigida por Rafael Cano Aguilar.

3. Me refiero al «Grupo de estudios de Prosa Hispánica Bajomedieval y Renacentista» de la Universidad Complutense de Madrid.

4. Vid. <http://pendientedemigracion.ucm.es/info/dialogycabddh/index.html>

5. Mi última consulta de esta base de datos en línea es del 30 de septiembre de 2015.

6. Entresaco la cita de Ana Vian (2010: clxxxii). 
primis la de Fabié), ${ }^{7}$ incluida esa maravilla del género epistolar $-\mathrm{y}$ del ingenio humano- que son sus cartas latinas y castellanas. Una feliz excepción la representan los seis diálogos con que se abre la antología de Almuzara. ${ }^{8}$ En lo que se refiere a los tres primeros (Diálogo de las fiebres interpoladas; ${ }^{9}$ Diálogo del calor natural; y Diálogo entre Villalobos y un grande), Consolación Baranda publicó el texto impreso en la prínceps de los Problemas (1543), pero no sin cotejar el primero y el tercero de ellos con las versiones manuscritas conservadas, de las que dio detallada noticia en las páginas liminares. Fue gracias a esta cuidadosa collatio que Baranda reparó en unas enjundiosas variantes relativas a un delicado pasaje de la conversación de Villalobos con el duque (seguramente de Alba), detectando un caso muy llamativo de autocensura. ${ }^{10}$

Que no se trataba de una mera curiosidad anecdótica lo demostró en un posterior artículo la misma estudiosa, ${ }^{11}$ quien, al hilo de una acertada intuición (basada en el dato filológico que acabo de mencionar), profundizó en el análisis del epistolario de Villalobos, arrojando nueva luz sobre las alusiones a sus orígenes judíos que lo constelan. ${ }^{12}$ En este sentido la ansiada edición moderna de dicho epistolario, ${ }^{13}$ que Consolación Baranda dará próximamente a la imprenta, nos brindará a buen seguro una mina de datos novedosos e imprescindibles para reorientar ciertas interpretaciones de las obras del médico real, como ha dejado patente un botón de muestra recién publicado. ${ }^{14}$

Paralelamente, un examen minucioso de los documentos archivísticos que Anastasio Rojo ha señalado hace poco ${ }^{15}$ ayudará a perfilar mejor la semblanza del doctor Villalobos, a conocer los avatares de su numerosa prole, ${ }^{16} \mathrm{y}$ a entender plenamente su firme rechazo de toda política discriminatoria contra los conver-

7. Antonio María Fabié (1886).

8. López de Villalobos (2010: 3-106).

9. Cuantos estén interesados en la vertiente médica e histórico-científica de este diálogo disponen ahora de un útil complemento a las notas del mismo: Anastasio Rojo Vega (2015a). Véanse sobre todo las pp. 52-53.

10. Cf. Baranda (2010: 13-14).

11. Vid. Baranda (2012).

12. «[...] las burlas sobre el linaje que intercambia el doctor Villalobos con sus corresponsales son muestra de complicidad y de una especial relación de confianza. El intercambio de motes tendría la función de subrayar y reforzar los vínculos que le sirvieron de apoyo a lo largo de su carrera profesional; estaríamos ante una variedad de la solidaridad vertical que operó como red de protección de muchos conversos e incluso criptojudíos a lo largo del siglo XvI». Baranda (2012: 30). 13. Al estudio de las cartas de Villalobos está dedicada la inédita tesis doctoral de David Leonardo Espitia Ortiz, «Una lectura de la obra epistolar del doctor Francisco López de Villalobos» (2004), dirigida por Gonzalo Pontón.

14. Vid. Baranda (2015). <http://www.ehumanista.ucsb.edu/volumes/volume_29/index.shtml>

15. Vid. Anastasio Rojo Vega (2015b). Los documentos en cuestión se citan en la p. 52.

16. Villalobos no dejó de mencionar a algunos de sus hijos tanto en las cartas como en los diálogos. Véase, por ejemplo, el Diálogo entre el Marqués de Lombay y Eco, en López de Villalobos (2010: 102). 
sos, del que da fe la notable epístola al General de la Orden de San Francisco. Importa recordar a este propósito el memorial que su hijo Gaspar presentó en marzo de 1535 (dejando constancia de la exclusión padecida en el colegio alcalaíno), y que se custodia actualmente entre los papeles de la Cámara de Castilla en el Archivo General de Simancas.

En cuanto al segundo bloque de diálogos editados por Baranda en 2010 (Diálogo entre Villalobos, su criado y Fray Martin; Diálogo entre el Marqués de Lombay y Eco; Diálogo entre Villalobos y la camarera de la reina),${ }^{17}$ los tres se han conservado solo en forma manuscrita, y además incompleta en el primero y en el tercer caso. El último texto quizá sea el más interesante, pese a su extrema brevedad, por la variedad de tonos y tintes del marco epistolar, junto con la riqueza de recursos propios de farsas y comedias. Tanto es así que ha merecido posteriormente un estudio exento por parte de Baranda, ${ }^{18}$ donde se proporcionan más detalles sobre las circunstancias de su redacción, las creencias de la coprotagonista portuguesa (que bien explican su reacción escandalizada ante tan escabrosa conversación), y se analizan a la vez dos marcas distintivas del Villalobos escritor: su "falta de conciencia de la autonomía del diálogo como género literario de larga tradición», y su habilidad "para rentabilizar al máximo los límites de sus horizontes genéricos». ${ }^{19}$

De argumento, estilo y contexto muy distintos es el anónimo Diálogo entre Caronte y el ánima de Pedro Luis Farnesio, hijo del Papa Paulo tercio, de claro corte lucianesco, cuya pubicación en la antología de Almuzara está al cuidado de José Antonio Lozano Sánchez. Es una pena que el lector no disponga de elemento alguno para valorar su labor ecdótica, culminada en la que él mismo presentó en la introducción como la primera edición crítica de este texto. Una edición fundada, según informaba Lozano, «en la construcción del estema a partir de la collatio de todos los manuscritos que he encontrado y consultado hasta el momento, nueve en total, la mayor parte perteneciente al siglo XVII». ${ }^{20}$ Ahora bien, si por un lado se entiende perfectamente que, de acuerdo con los criterios de la Biblioteca de Literatura Universal, en su prólogo no haya podido tener cabida el aparato crítico del diálogo, por otro es cuanto menos discutible (por no decir incomprensible) que se haya omitido toda referencia a la ubicación de los códices estudiados.

No es cuestión baladí, puesto que la nómina de los testimonios de la obra se ha ido incrementando en los últimos años. Baste pensar que, en su primera edi-

17. A decir verdad, aunque éste debería ser el orden de secuencia por razones cronológicas (orden anunciado en la introducción de Baranda, y reproducido tanto en el índice del volumen como en la portadilla de la p. 3), en realidad el que cierra la sección de la antología dedicada a Villalobos es el diálogo del Marqués de Lombay y Eco.

18. Baranda (2013).

19. Baranda (2013: 152).

20. Cf. Lozano Sánchez (2010: 488). 
ción moderna (1855), Adolfo de Castro se limitó a indicar que «en la Biblioteca Nacional existen antiguas copias manuscritas de este ingenioso opúsculo», ${ }^{21} \sin$ aclarar qué ejemplar había transcrito; ${ }^{22}$ en la segunda (1914) Alfred Morel-Fatio puntualizó que, para mejorar el texto reproducido por Castro, lo había colacionado con el «d'une copie du XVII siècle insérée dans un volume de mélanges de la Bibliothèque Nationale de Paris, Espagnol 354»;23 y en la tercera (2004) José López Romero declaró haber incorporado a la edición de Morel-Fatio, tomada como base, las variantes más significativas de dos códices de la Biblioteca Nacional de Madrid, el ms. 287 y el ms. 6149. ${ }^{24}$

Una elección singular y no motivada la de López Romero, visto que no cotejó todos los ejemplares conocidos hasta la fecha, sino solo dos de ellos, uno de los cuales (ms. 6149) además está incompleto. Y eso pese a remitir en su introducción a los trabajos de Foulché-Delbosc y Simón Díaz, quienes efectivamente dieron "cumplida noticia" de las diversas copias manuscritas del libelo. El bibliógrafo francés llegó a contar seis, sumando a la parisina, publicada por Morel-Fatio, cuatro de la Nacional de Madrid, ${ }^{25}$ y una de la Biblioteca Imperial de San Petersburgo (Petrogrado en aquel entonces), ${ }^{26}$ de la que hoy día se ha perdido el rastro.

Por su parte, José Simón Díaz ${ }^{27}$ enumeró cinco, es decir, las cuatro de la Nacional española, más otra de la Biblioteca Menéndez Pelayo de Santander $\left(\mathrm{n}^{\circ} 82\right),{ }^{28}$ pero incluyó en su repertorio también un resumen de la obra transcrito en el siglo XvII, que sigue guardándose en la Real Academia de la Historia de Madrid, con signatura 9-833. ${ }^{29}$

21. Adolfo de Castro (1855: vii).

22. Es muy probable que fuera uno de los que mencionó en dos trabajos previos a su edición de 1855. Al publicar un extracto del diálogo en El buscapié, Castro (1848: 64) presentó el texto de esta forma: «escribió don Diego de Mendoza una escelente [sic] obrita que existe MS en mi biblioteca». Al año siguiente, citó en un artículo dos ejemplares manuscritos, uno conservado en la Biblioteca Colombina y otro «en la de mi amigo el Sr. D. Joaquín Rubio, anticuario gaditano». Véase Adolfo de Castro (1849: 2). Según me ha comunicado don José Francisco Sáez Guillén, jefe de la Sección de Bibliotecas de la Institución Colombina, a quien agradezco sus pesquisas, el códice sevillano se encuentra actualmente en paradero desconocido.

23. Alfred Morel-Fatio (1914: 127).

24. Véase la nota al texto de José López Romero ed. (2004: 25-26).

25. Los citó por las signaturas antiguas, C. 141 , Cc. 180 , R. 5, X. 53, que hoy día se han convertido respectivamente en mss. 287, 9673, 6149, 8755.

26. Foulché-Delbosc (1915: 8) sacó la información sobre el ejemplar ruso de un catálogo publicado en la Revista de Archivos $(6,1876)$ donde figuraba, entre otros manuscritos españoles, uno facticio que contenía el Diálogo a la muerte de Pedro Luis Farnés.

27. José Simón Díaz (1976: 686-687, nn 5693-5698).

28. El número se refiere a la correspondiente entrada del Catálogo de los manuscritos de la Biblioteca Menéndez y Pelayo publicado por Miguel Artigas en 1930. Agradezco a la directora de la biblioteca santanderina, doña Rosa Fernández Lera, el haberme facilitado la signatura actual del códice, M-144 bis.

29. Volveré más adelante sobre este compendio. 
En 2005 María Teresa Cacho permitió elevar a siete los testimonios localizados hasta la fecha, señalando, aunque de forma muy escueta, el de la Biblioteca Nacional de Florencia ${ }^{30}$ (Fondo Magliabechiano, Classe VIII, 26 Marmi $\mathrm{NC} / 22) .{ }^{31}$ Se trata de un volumen extremadamente interesante al menos por dos razones: no solo es una de las varias y jugosas misceláneas hispánicas copiadas a principios del XVII en Salamanca por o para el caballero florentino Girolamo da Sommaia, ${ }^{32}$ sino que en la portadilla del Diálogo a la muerte de Pedro Luis Farnés se lee la fecha de 1547, lo cual corrobora la hipótesis de cuantos creen que el libelo se redactó inmediatamente después del asesinato del hijo de Paulo III (como todo instant book que se precie). Una opinión, ésta, no compartida por Lozano Sánchez, quien, a todas luces, ni manejó ni conoció el códice magliabechiano, al apuntar a 1549 como a la "fecha más probable de composición [...] pues los dos únicos manuscritos que lo datan coinciden en ese año». ${ }^{33}$

La lista de testimonios de la obra no termina aquí, ya que María José Bertomeu Masià añadió en 2013 el que se custodia en la Biblioteca Casanatense de Roma con signatura ms. $2263 ; 3^{34}$ y yo, por mi parte, voy a aportar dos más, ambos conservados en Madrid: uno en la Biblioteca Nacional, y otro en la de la Real Academia de Historia. El primero (ms. 12975/35), que está digitalizado, ${ }^{35}$ es presumiblemente un apógrafo del ms. Espagnol 354, puesto que - al igual que el de la Biblioteca Menéndez Pelayo, dicho sea de paso-, lleva en la portadilla la siguiente nota: «se trasladó de una copia que sacó en París el jesuita P. José Petisco». El manuscrito, sin duda alguna posterior a la segunda mitad del XVIII, ${ }^{36}$ en el catálogo online de la Nacional está datado en el siglo XIx.

30. Cf. María Teresa Cacho (2005). Véase especialmente la nota 14 de p. 66.

31. Para ser exactos, la misma filóloga ya había clasificado y descrito dicho códice en una publicación anterior. Cf. María Teresa Cacho (2001: I, 111).

32. La portada del manuscrito magliabechiano reza: «Ad usum Hieronymi Summarij Patricij Florentini. / [...] Salmanticae Año MDVI. [falta una C]». Vid. María Teresa Cacho (2001: I, 108). Para una biografía detallada de Girolamo da Sommaia, quien residiera en Salamanca entre 1599 y 1607 cursando Leyes y Cánones, remito a George Haley ed. (1977: 9-35). La edición de Haley fue reimpresa en 2012 por la Universidad de Málaga (como anejo 83 de la revista Analecta Malacitana) con un prólogo de Gaspar Garrote Bernal a modo de status quaestionis, y una nota preliminar del mismo Haley, el cual se encargó, además, de actualizar su introducción y de corregir el texto del diario.

33. Véase Lozano Sánchez (2010: 488).

34. Cf. María José Bertomeu Masià (2013: 63-74). Para una descripción sumaria del testimonio casanatense, véase p. 68. Bertomeu Masià ya se había ocupado anteriormente del Diálogo entre Caronte y el ánima de Pedro Luis Farnesio en una monografía sobre la cuestión del ducado de Parma y Piacenza, en la que, sin embargo, los manuscritos citados no pasaban de cinco. Cf. María José Bertomeu Masià (2009: 99-101).

35. Cf. $<$ http://bdh-rd.bne.es/viewer.vm?id=0000146883\&page $=1>$

36. Está documentada entre 1751 y 1754 una larga estancia (por motivos de estudio) en Francia del Padre Petisco, célebre helenista y biblista español, que en este arco temporal debió realizar su copia. Cf. Gabriel Ma Verd (2001: 3115-3116). 
Se remonta, en cambio, al xvir el testimonio de la Academia de la Historia, titulado Diálogo entre Charón Estigio, varquero, y el ánima de Pedro Luis Farnesio, hijo del Papa Paulo Terçio, ${ }^{37}$ que se encuentra en los ff. 45v-54v del ms. 9/420 (olim F-12). La transcripción del texto se trunca bruscamente en el folio 54v, dejando a medias una larga réplica de Carón, justo después de que éste mencionara a los mercenarios suizos contratados por Pedro Luis para ocupar Lombardía: "contome la gran manada de puercos que tenías ya aparejada en tierra de Suyços para traerlos a la carneçería de Lombardía, y Leoneses [sic]». ${ }^{38}$

Importa destacar que la Biblioteca de la Real Academia de la Historia posee también dos códices misceláneos que incluyen sendos compendios de la obra, ${ }^{39}$ cuyos encabezamientos bastarían por sí solos para replantear la controvertida cuestión de su paternidad: Suma de lo que se contiene en un diálogo que dicen ordenó Don Diego de Mendoza sobre la muerte de Pedro Luis Farnesio.

Por supuesto no es éste el lugar para profundizar en la dudosa autoría del diálogo, pero sí quiero poner de relieve que la letra de uno de los dos resúmenes es del siglo XVI, mientras que los testimonios más antiguos del texto integral que nos han llegado son del xvir. No me parece descabellado imaginar que, junto con las primeras copias manuscritas, empezara a circular también el rumor (más o menos fundado) de que el libelo anti-farnesiano estaba hecho por encargo del entonces embajador en Roma, don Diego Hurtado de Mendoza. Una vez asociado su nombre a ese pamphlet, no es de extrañar que, con el paso del tiempo, el papel del diplomático español se haya podido transformar de committente a autor. Al igual que Adolfo de Castro en su momento, también Lozano Sánchez se inclinó por ahijárselo, ${ }^{40}$ sin embargo, en cada una de las cuatro ediciones modernas recordadas aquí $(1855,1914,2004$ y 2010) el texto se ha publicado siempre como anónimo, ${ }^{41} \mathrm{y}$, a la luz de que he venido exponiendo, creo que merecerían ser tenidas en debida cuenta propuestas de afiliación alternativa. ${ }^{42}$

37. En el catálogo de la Colección Salazar y Castro se registra un título algo distinto: Diálogo entre Charón Estigio, barquero, y el alma de Pedro Luis Farnesio, I duque de Palma [sic] (1490-1547), asesinado por sus súbditos. Cf. <http://www.rah.es/pdf/SalazaryCastro.pdf>, p. 5366.

38. El pasaje se encuentra en las pp. 516-517 de la edición al cuidado de Lozano Sánchez.

39. Uno es el ms. 9-833 (olim M-26) mencionado por Simón Díaz (cf. las notas 27 y 29 del presente trabajo); el otro es el ms. 9-1049 (olim N-44).

40. Lozano Sánchez (2010: 487) apuntó que «existen algunos datos para reconsiderar el diálogo como fruto del escritor de La Guerra de Granada», presentando fugazmente los más relevantes a su entender.

41. Fue incluido, en cambio, en las Obras de D. Diego Hurtado de Mendoza coleccionadas por Nicolás del Paso y Delgado (1864: 297-315), y en las Obras en prosa de D. Diego Hurtado de Mendoza (1881: 399-423).

42. Ángel González Palencia y Eugenio Mele (1943: III, 204) sugirieron que el anónimo autor fuera «algún agente imperial en Roma». María Teresa Cacho (2005: 76), al excluir que el diálogo saliera de la pluma del diplomático granadino, declaró no albergar duda alguna de que fuera «obra de alguien de su entorno", mientras que Rosa Navarro (2011a; 2011b: 127-149) alegó numerosas concordancias léxicas para atribuírselo a Jerónimo de Urrea. 
Por último, no puedo dejar de observar que Lozano Sánchez pasó en absoluto silencio la existencia de una versión italiana de la obra que editó. ${ }^{43} \mathrm{~A}$ mi juicio hubiera sido oportuno mencionarla, y de gran interés hacerse eco del valioso trabajo de Carlo Ossola ${ }^{44}$ que permite aclarar las circunstancias histórico-políticas en que se fraguaron tanto el original español de 1547, como su posterior traducción (suavizada en algunos puntos sensibles) de 1549.

Es de esperar que vea pronto la luz el estudio anunciado por Lozano Sánchez en su introducción, estudio en el que quizá se amplíen e integren las informaciones acerca de la transmisión manuscrita (en castellano y en italiano) del Diálogo entre Caronte y el ánima de Pedro Luis Farnesio, lo que permitiría resolver algunas de las dudas planteadas aquí.

Cierran la antología de Almuzara los Diálogos de apacible entretenimiento de Gaspar Lucas Hidalgo, seleccionados por la coordinadora del volumen, pese a su fecha algo tardía, por ser "producto pleno y coronación de la estética quinientista, $y$ por tanto susceptible de agruparse por afinidad con el corpus fijado, a la vez que principio de algunos de los cambios que han de sobrevenir en esta especie». ${ }^{45}$

El destino editorial de dichos diálogos no puede sino tildarse de singular: a la prínceps de 1603 (hoy perdida) ${ }^{46}$ siguieron, en el arco de un quindenio, al menos seis reimpresiones, certificando su éxito comercial. Una vez incluida en el Índice de Zapata (1632), la obra dejó de publicarse hasta el siglo XIx (1855 y 1884), siendo víctima en una ocasión de notables cortes censorios, $y$, tras un largo silencio, ${ }^{47}$ por un capricho de la suerte conoció en 2010 dos ediciones distintas (aparecidas la una al principio, la otra a finales del año), al cuidado, respectivamente, de Julio Alonso Asenjo y Abraham Madroñal (Publicacions de la Universitat de València), y de Jesús Gallego Montero (Almuzara). ${ }^{48}$

Viene al caso evidenciar que la edición anotada y el estudio introductorio de los Diálogos de apacible entretenimiento aparecidos en el volumen de Almuzara no eran sino un adelanto de la tesis doctoral (dirigida por Ana Vian) que el mismo Gallego Montero leyó en diciembre de 2010, y que puede consultarse como recurso electrónico de la Universidad Complutense de Madrid. ${ }^{49}$ Me li-

43. Solo en la n. 102 de p. 522 hay una lacónica referencia a un no mejor identificado «manuscrito italiano".

44. Cf. Carlo Ossola (1987: 101-127), ya publicado en Amedeo Quondam ed. (1978: II, 273301).

45. Ana Vian (2010: clxxxii).

46. Fue Gallego Montero quien documentó su existencia, registrando una mención de la misma en el «Inventario de los libros prohibidos por el Tribunal de Santiago» (1709). Cf. la tesis doctoral que señalo en la nota 49.

47. Lo interrumpió solo una reimpresión de la edición de 1855, llevada a cabo en 1950.

48. Los tres coincidieron en elegir como texto base el de la primera edición barcelonesa salida del taller de Sebastián de Cormellas, aunque no el del mismo ejemplar.

49. Vid. <http://eprints.ucm.es/12419/1/T32815.pdf> 
mitaré aquí a subrayar el esmero de ambas ediciones de 2010 (en cierto modo complementarias), sin entrar en detalles sobre los enfoques y criterios adoptados en cada una de ellas. Me exime de hacerlo, además, el postscriptum que Gallego Montero redactó cuando ya tenía zanjada su investigación: ${ }^{50}$ no es sino una reseña crítica del trabajo de Asenjo y Madroñal, en la que se ahonda en algunos aspectos ecdóticos, en la cuestión de la autoría de la obra, y en la del género literario al que cabe adscribirla, desde luego la más espinosa y conflictiva, debido a su extremado hibridismo.

De este último tema se ha ocupado recientemente Jesús Gómez, al analizar el «desplazamiento desde el carácter pedagógico que subyace en los diálogos renacentistas [...] de acuerdo con el equilibrado ideal horaciano prodesse-delectare, presente en la dicotomía burlas-veras habitual en la época, a favor de las burlas y de la amenidad predominantes en los relatos cómicos que recopila Hidalgo». ${ }^{51}$

El menor protagonismo que Hidalgo otorgó en su obra al componente argumentativo caracterizaría también algún que otro producto del mismo género literario en las décadas siguientes. Sin embargo, el estudio de la evolución del diálogo en el XVII ha sido, en general, desatendido por parte de la crítica, salvo contadas excepciones. Entre ellas sobresale la reciente monografía de Jesús Gómez, ${ }^{52}$ quien ha puesto de relieve cierta penuria de bibliografía específica, y máxime de ediciones críticas, que resalta aún más «frente a la abundancia relativa sobre la centuria anterior». ${ }^{53}$ Confiemos en que pronto, a la valiosa antología coordinada por Ana Vian, pueda sumarse otra, de igual solvencia y provecho, que reúna los diálogos españoles más representativos de la época barroca.

50. Ibidem, pp. 343-356.

51. Jesús Gómez (2013: 151).

52. Vid. nota 2.

53. Jesús Gómez (2015: 19). 


\section{Bibliografía}

Baranda, Consolación, «Introducción» a Francisco López de Villalobos, Diálogos, en Ana Vian (coord.), Diálogos españoles del Renacimiento, ToledoMadrid-Córdoba, Almuzara (Biblioteca de Literatura Universal), 2010, pp. 5-17.

—, «Las cartas de Francisco López de Villalobos: redes sociales, origen converso y solidaridad vertical», Librosdelacorte.es, no 5 año 4, otońo-invierno, 2012, pp. 9-30.

—, «Villalobos y La camarera de la reina (1533): diálogo literario», en Felipe González Alcázar, Fernando Ángel Moreno Serrano, Juan Felipe Villar Dégano (eds.), Literatura, pasión sagrada. Homenaje al profesor Antonio García Berrio, Madrid, Departamento de Lengua Española, Teoría de la Literatura y Literatura Comparada, Universidad Complutense de Madrid, 2013, pp. 143-153.

—, «El humanismo frustrado de Francisco López de Villalobos y la polémica con Hernán Núñez», eHumanista, 29 (2015), pp. 208-239. <http://www. ehumanista.ucsb.edu/volumes/volume_29/index.shtml>

Bertomeu Masià, María José, La guerra secreta de Carlos V contra el Papa. La cuestión de Parma y Piacenza en la correspondencia del cardenal Granvela, Valencia-Murcia, Publicacions de la Universitat de València-Ediciones de la Universidad de Murcia, 2009.

—, "La traducción italiana de un diálogo español del siglo XVI», en Estela González de Sande y Mercedes González de Sande (eds.), Las relaciones italo-españolas: traducción, lengua y literatura, Sevilla, Arcibel Editores, 2013, pp. 63-74.

Cacho, María Teresa, Manuscritos hispánicos en las bibliotecas de Florencia, Firenze, Alinea, 2001, 2 vols.

—, «Función de la actualidad en el diálogo renacentista: el Diálogo entre Caronte y el Alma de Pedro Luis Farnesio», en Pierre Civil y Danielle Boillet (coords.), L'actualité et sa mise en écriture aux $X V^{E}-X V I^{e}$ et $X V I I^{e}$ siècles. Espagne, Italie, France et Portugal, Paris, Presses Sorbonne Nouvelle, 2005, pp. 63-76.

Castro, Adolfo de (ed.), El buscapié, Cádiz, Imprenta, Librería y litografía de la Revista Médica, 1848.

Castro, Adolfo de, «D. Diego Hurtado de Mendoza», en La Tertulia. Periódico semanal de literatura y de artes, 14 de enero de 1849, pp. 1-4.

—, Prólogo a Idem (ed.), Curiosidades bibliográficas. Colección escogida de obras raras de amenidad y erudición, Madrid, Rivadeneyra, 1855 (tomo 36 de la Biblioteca de Autores Españoles), pp. vii-x.

Fabié, Antonio María, Algunas obras del doctor Francisco López de Villalobos, Madrid, Sociedad de Bibliófilos Españoles (Imprenta de Miguel Ginesta), 1886.

Foulché-Delbosc, Raymond, «Les oeuvres attribuées à Mendoza», en Revue Hispanique, XXXII (1915), pp. 1-86. 
Gallego Montero, Jesús, Edición crítica y estudio de los Diálogos de apacible entretenimiento de Gaspar Lucas Hidalgo, tesis doctoral bajo la dirección de Ana Vian Herrero (2010). <http://eprints.ucm.es/12419/1/T32815.pdf>

Gómez, Jesús, «La amenidad del relato breve en los Diálogos de apacible entretenimiento», en Valentín Núñez Rivera (ed.), Ficciones en la ficción. Poéticas de la narración inserta (siglos XV-XVII), Bellaterra, Servei de Publicacions de la Universitat Autònoma de Barcelona, 2013 (Studia Aurea Monográfica 4), pp. 145-165.

-, Tendencias del diálogo barroco. Literatura y pensamiento durante la segunda mitad del siglo XVII, Madrid, Visor Libros, 2015.

González Palencia, Ángel, y Mele, Eugenio, Vida y obras de don Diego Hurtado de Mendoza, Madrid, Instituto Valencia de Don Juan, 1943, 3 vols.

Haley, George (ed.), Diario de un estudiante de Salamanca. La crónica inédita de Girolamo da Sommaia (1603-1607), Salamanca, Universidad - Secretariado de Publicaciones e Intercambio Científico, 1977.

Hidalgo, Gaspar Lucas, Diálogos de apacible entretenimiento, estudio y edición de Julio Alonso Asenjo y Abraham Madroñal Durán, València, Publicacions de la Universitat de València, 2010.

-, Diálogos de apacible entretenimiento, introducción, edición y notas de Jesús Gallego Montero, en Ana Vian (coord.), Diálogos españoles del Renacimiento, Toledo-Madrid-Córdoba, Almuzara (Biblioteca de Literatura Universal), 2010, pp. 1235-1418.

Hurtado de Mendoza, Diego, Obras en prosa, Madrid, Luis Navarro, 1881.

López de Villalobos, Francisco, Diálogos, introducción, edición y notas de Consolación Baranda, en Ana Vian (coord.), Diálogos españoles del Renacimiento, Toledo-Madrid-Córdoba, Almuzara (Biblioteca de Literatura Universal), 2010, pp. 3-106.

López Romero, José (ed.), Diálogo entre Caronte y el ánima de Pedro Luis Farnesio, hijo del Papa Paulo III, Sevilla, Alfar, 2004.

Lozano Sánchez, José Antonio, "Introducción» a Anónimo, Diálogo entre Caronte y el ánima de Pedro Luis Farnesio, hijo del Papa Paulo tercio, en Ana Vian (coord.), Diálogos españoles del Renacimiento, Toledo-MadridCórdoba, Almuzara (Biblioteca de Literatura Universal), 2010, pp. 479-488.

Morel-Fatio, Alfred, "Dialogue entre Charon et l'âme de Pierre-Louis Farnèse», en Bulletin Italien, vol. XIV, 1914, pp. 126-157.

Navarro, Rosa, «El Diálogo entre Caronte y el ánima de Pedro Luis Farnesio: un libro abierto», Clarin, no 91, 2011a, pp. 3-7.

-, Tres personajes satíricos en busca de su autor. Lázaro de Tormes, el atún Lázaro y Caronte en su diálogo con Pedro Luis Farnesio, Valladolid, Universidad de Valladolid, 2011b.

Ossola, Carlo, «Il 'luogo' della Corte e le sue 'rappresentazioni'» en Idem, Dal Cortegiano allUomo di mondo, Torino, Einaudi, 1987, pp. 101-127. 
Paso y Delgado, Nicolás del (ed.), Obras de D. Diego Hurtado de Mendoza, Granada, El Porvenir, 1864. (Es el primer tomo de la Biblioteca de escritores granadinos desde la civilización árabe hasta nuestros días).

Quondam, Amedeo (ed.), Le corti farnesiane di Parma e Piacenza: 1545-1622, Roma, Bulzoni, 1978, 2 vols.

Rey Quesada, Santiago del, Diálogo y traducción: los Coloquios erasmianos en la Castilla del s. XVI, Tübingen, Narr Verlag, 2015.

Rojo VegA, Anastasio, «El doctor Francisco López de Villalobos y las calenturas», Revista española de investigaciones quirúrgicas, vol. XVIII, no 1, 2015a, pp. 49-56.

—, «El doctor Villalobos: de niño judío a converso burlador», Revista iberoamericana de cirugía vascular, vol. 3, no 1, 2015b, pp. 49-57.

Simón DíAz, José, Bibliografía de la literatura hispánica, Madrid, CSIC, 1976, t. XI.

Vega, María José y Vian, Ana (eds.), Diálogo y censura en el siglo XVI (España y Portugal), Madrid-Frankfurt, Iberoamericana Vervuert, en prensa.

Verd, Gabriel Ma, "José Manuel Petisco» en Charles E. O’Neill, Joaquín Ma Domínguez (dirs.), Diccionario histórico de la Compañia de Jesús, Madrid, Universidad Pontificia Comillas - Roma, Institutum historicum, 2001, vol. 3, pp. 3115-3116.

VIAN, Ana (coord.), Diálogos españoles del Renacimiento, Toledo-Madrid-Córdoba, Almuzara (Biblioteca de Literatura Universal), 2010.

VIAN, Ana, «Introducción» a Eadem (coord.), Diálogos españoles del Renacimiento, Toledo-Madrid-Córdoba, Almuzara (Biblioteca de Literatura Universal), 2010, pp. xiii-cxci. 